\title{
Second endoscopic retrograde cholangiopancreatography after failure of initial biliary cannulation: $A$ single institution retrospective experience
}

\author{
XIN DENG, RUI LIAO, LONG PAN, CHENGYOU DU and QIAO WU \\ Department of Hepatobiliary Surgery, The First Affiliated Hospital of Chongqing Medical University, \\ Chongqing 400016, P.R. China
}

Received December 9, 2021; Accepted February 1, 2022

DOI: $10.3892 /$ etm.2022.11226

\begin{abstract}
Endoscopic retrograde cholangiopancreatography $(\mathrm{ERCP})$ is not always successful when difficult biliary cannulation occurs. A second ERCP seems to be a worthwhile option following initial failure cannulation; however, relevant data are limited. Thus, the aim of the present study was to determine the outcomes of repeating ERCP in patients in whom the first biliary cannulation with or without precut sphincterotomy failed. It retrospectively analyzed 4,136 patients who underwent an initial biliary access between June 2016 and September 2020. Data from our databases were analyzed. Efficacy was based on the cannulation rate of the second ERCP and safety was assessed in terms of adverse events. Of 94 patients, $56(59.6 \%)$ underwent a second ERCP and the success rate in biliary cannulation was $83.9 \%$ (47 of 56). The median operative time in the second ERCP was shorter than that in the initial procedure ( $47 \mathrm{vs} .65 \mathrm{~min}, \mathrm{P}<0.001)$. A total of 5 patients $(8.9 \%)$ suffered from mild ERCP-associated complications following the second ERCP. Compared with patients that did not undergo a second ERCP, patients that underwent a second ERCP had a lower 30-day mortality rate (13.2 vs. $1.8 \%$, $\mathrm{P}=0.038$ ). In addition, by univariate and multivariate analysis, it was observed that normal preoperative serum bilirubin levels and an interval time of $<3$ days were correlated with the cannulation failure of a second $\mathrm{ERCP}(\mathrm{OR}=9.211, \mathrm{P}=0.019$, $\mathrm{OR}=6.765, \mathrm{P}=0.041$, respectively). A second $\mathrm{ERCP}$ following failure of an initial biliary cannulation appears to be safe and effective. For most clinically stable patients with an unsuccessful initial ERCP, a second ERCP after 2-4 days may be an optimal strategy. Preoperative normal serum bilirubin levels
\end{abstract}

Correspondence to: Dr Qiao Wu, Department of Hepatobiliary Surgery, The First Affiliated Hospital of Chongqing Medical University, 1 Youyi Road, Yuzhong, Yuanjiagang, Chongqing 400016, P.R. China

E-mail: wuqiao001268@163.com

Key words: endoscopic retrograde cholangiopancreatography, difficult biliary cannulation, needle-knife, predictive factors may be a risk factor that can be used for predicting cannulation failure of a second ERCP procedure.

\section{Introduction}

Endoscopic retrograde cholangiopancreatography (ERCP) has become the preferred diagnostic and therapeutic option for a number of pancreaticobiliary conditions. However, it is not always successful even with experienced hands or in high-volume medical centers $(1,2)$. It is known that selective biliary cannulation is key to ERCP and the following treatments, according to studies, bile duct cannulation fails in patients at a rate ranging between 5 and $15 \%(3,4)$. In most cases, patients with small duodenal papilla, papilla opening sclerosis, papilla looseness, peripapillary diverticulum and surgically altered anatomy are more likely to undergo unsuccessful biliary cannulation (5-8). Alternative methods, including repeat ERCP, percutaneous-endoscopic or endoscopic ultrasound-guided rendezvous procedures, percutaneous transhepatic biliary therapy and surgical intervention, can be chosen to gain biliary access following the failure of initial ERCP (9-14). However, these technical alternatives to a second ERCP following the initial failure procedure still have several limitations, such as their invasiveness and morbidity, and they are not as widely available as ERCP $(9,10)$. Furthermore there is no consensus in the guidance of handling patients with failed biliary cannulation at the initial ERCP and the issues of a second ERCP, such as the optimal interval time and risk factors for cannulation failure, need to be solved.

Therefore, this retrospective study investigated whether it is justifiable to conduct a second ERCP within a short time interval following an initial failure caused by a difficult cannulation. It also aimed to identify risk factors for a second ERCP.

\section{Materials and methods}

Data collection. A retrospective study of all patients who underwent ERCP between June 2016 and September 2020 in the Department of Hepatobiliary Surgery at the First Affiliated Hospital of Chongqing Medical University was conducted. All patients with native papilla who underwent ERCP for the first time with an initial failure of these procedures that was 
attributed to difficult biliary cannulation were included. The exclusion criteria were as follows: Age $<18$ years, invisible major duodenal papilla, selective pancreatic duct cannulation and lack of requested data in the database.

Data for each ERCP procedure were retrieved from the database system of the First Affiliated Hospital of Chongqing Medical University (Chongqing, China). Patients' main details, indications for ERCP, technical details of the procedures, final diagnoses, procedure-related complications, perioperative biochemical indices and follow-up data were recorded. All patients gave written informed consent before ERCP. The study was approved by the ethical review board at the First Affiliated Hospital of Chongqing Medical University (no. 2020-668).

ERCP procedure. An experienced endoscopist and a professional nurse (performing $>200$ ERCPs per year) performed all endoscopic procedures with fluoroscopic assistance and using a therapeutic duodenoscope (PENTAX ED34-i10T 4.2; Pentax Medical) and endoscopic accessories (Boston Scientific and Olympus Corporation). The commonly used advanced cannulation techniques included double-guidewire (DGW) technique and needle-knife sphincterotomy (NKS).

All patients fasted routinely for $8 \mathrm{~h}$ before the operation. At $30 \mathrm{~min}$ before the procedure, patients were consciously sedated with intramuscular anisodamine $10 \mathrm{mg}$, pethidine and diazepam (the dose was determined according to the condition of patients). Usually, standard biliary cannulation was performed with the guidewire-assisted technique. A double lumen pull-type sphincterotome (Olympus Corporation) preloaded with a hydrophilic guidewire (Hydra Jagwire; Boston Scientific) was used in this technique. However, if the guidewire was put into the pancreatic duct more than twice, the guidewire had to be kept in the pancreatic duct and the DGW technique had to be used. If standard biliary cannulation was unsuccessful and DGW was not performed or failed, NKS would be used. NKS was performed with a needle-knife sphincterotome (Triple-lumen Microknife XL; Boston Scientific). The needle tip was anchored over the incarcerated calculus or directly on the summit of the protuberant papilla and then a puncture was made in the papilla above the orifice. If biliary cannulation could not succeed through this opening, a more extended incision was made upward stepwise along the axis of the bile duct from the papillary orifice. When the opening of the distal bile duct was exposed, it became possible to cannulate selectively with a guide wire passed through a sphincterotome. In addition, NKS or DGW was performed in the second ERCP procedure when standard cannulation could not be achieved.

The criteria of conducting second ERCP were as follows: i) Patients' clinical condition was stable; ii) patients agreed to attempt a second ERCP; iii) The endoscopist in the department recommended a second attempt at biliary cannulation; iv) other experts in the department agreed that a successful second ERCP might be more beneficial than other options.

Outcomes and definition. The primary outcome measure was the efficacy and safety of a second ERCP following initially failed. ERCP was deemed successful if biliary access was achieved enabling appropriate therapy.
Difficult biliary cannulation was defined by the presence of $\geq 1$ of the following: $>5$ contacts with the papilla whilst attempting to cannulate, inability to achieve selective biliary cannulation by standard technique within $10 \mathrm{~min},>1$ unintended pancreatic duct cannulation or failure of access to the major papilla $(15,16)$.

'Expert endoscopist' was defined as one having performed $>1,000$ ERCPs during their career and who could perform procedures equivalent to Grade 3 of the grading scale for the difficulty of ERCP, based on the ERCP core curriculum, without assistance (17-20).

Procedure-related complications were defined as adverse clinical events or unexpected clinical outcomes related to the procedure. Specifically, the present study assessed 30-day mortality, post-ERCP pancreatitis (PEP), bleeding, cholangitis, perforation and any unexpected adverse clinical event (21). PEP was defined as abdominal pain and an increase of serum amylase levels at least three times greater than the normal upper limit requiring hospitalization for at least 2 nights (21).

The secondary outcomes were the risk factors for cannulation failure of the second ERCP.

Statistical analysis. Continuous variables were measured as median with range and categorical variables were measured as frequencies (percentages). Statistical analyses for comparing outcomes of the two groups were performed with Mann-Whitney U test. For categorical data, the Chi-square or the Pearson's corrected Chi-square test was used where appropriate. Unconditional logistic regression analysis was performed to identify predictors associated with the second ERCP cannulation failure. Differences were considered statistically significant with a two-sided P-values of $<0.05$. All statistical analyses were performed by using SPSS software (v 24.0; IBM Corp.).

\section{Results}

General description. A total of 4,136 ERCPs were performed during this period. Of these, $579(15.2 \%)$ ERCPs referred to difficult cannulation. A total of 94 patients (2.3\%) who met the study inclusion criteria were identified. The median age of the cohort was 68 years (range 18-92); 57 (60.6\%) were female. The indications for ERCP included benign stricture (32 patients, 34\%), malignant stricture (25 patients, $26.6 \%$ ) and choledocholithiasis (37 patients, 39.4\%). The baseline characteristics of the study cohort are summarized in Table I. A second ERCP was performed in 56 patients with persistence of the initial clinical indication and stable condition following initial failure to gain biliary access. Among the remaining 38 patients, nine underwent percutaneous transhepatic biliary drainage (PTBD), 21 underwent surgery, seven did not undergo a second ERCP due to clinical improvement or patient refusal and one died due to rapid clinical deterioration and could not undergo any treatment (Fig. 1).

Second ERCP outcomes. For the 56 patients in whom a second ERCP was attempted, biliary access was achieved in 47 cases, equating to a success rate of $83.9 \%$. The nine failed second ERCP patients did not undergo a third ERCP. Of these, two were discharged with conservative treatment, two refused 
Table I. Demographic and baseline characteristics of patients and procedures with initial biliary cannulation failed.

\begin{tabular}{|c|c|}
\hline Initial failed biliary cannulation patients & $\mathrm{n}=94$ \\
\hline Median age, years (range) & $68.0(18.0-92.0)$ \\
\hline Sex female, $\mathrm{n}$ & $57(60.6 \%)$ \\
\hline \multicolumn{2}{|l|}{ Indications, $\mathrm{n}$} \\
\hline Benign stricture & $32(34 \%)$ \\
\hline Malignant stricture & $25(26.6 \%)$ \\
\hline Choledocholithiasis & $37(39.4 \%)$ \\
\hline Initial median operative time, minutes (range) & $60.5(25-141)$ \\
\hline Median hospital stay, days (range) & $14(1-41)$ \\
\hline Total bilirubin before first ERCP, median (range) $(\mu \mathrm{mol} / \mathrm{l})$ & $37.7(6.9-562.9)$ \\
\hline Days between ERCP, median (range) & $3(1-9)$ \\
\hline Adverse events after first ERCP, $n$ & $9(9.6 \%)$ \\
\hline Perforation & $1(1.1 \%)$ \\
\hline Pancreatitis & $5(5.3 \%)$ \\
\hline Cholangitis & $2(2.1 \%)$ \\
\hline Hemorrhage & $1(1.1 \%)$ \\
\hline 30-day mortality, $\mathrm{n}$ & $6(6.25 \%)$ \\
\hline Second ERCP, n & $56(59.6 \%)$ \\
\hline Second cannulation success, n (\%) & $47 / 56(83.9 \%)$ \\
\hline Adverse events after second ERCP, $n$ & $5 / 56(8.9 \%)$ \\
\hline Perforation & 0 \\
\hline Pancreatitis & $3 / 56(5.3 \%)$ \\
\hline Cholangitis & $2 / 56(3.6 \%)$ \\
\hline Hemorrhage & 0 \\
\hline
\end{tabular}

ERCP, endoscopic retrograde cholangiopancreatography.



Figure 1. The flow chart of management of patients in study cohort. PTBD, percutaneous transhepatic biliary drainage; ERCP, endoscopic retrograde cholangiopancreatography.

subsequent therapy and left the hospital and five chose to accept surgery. The second ERCP was performed a median of 3 days (interquartile range 2-4.25 days) following the initial unsuccessful biliary cannulation. Table II shows that the median operative time was significantly shorter (47 vs. $65 \mathrm{~min}$, $\mathrm{P}<0.001)$ and the number of applications of auxiliary cannulation techniques was significantly higher ( 39 vs. $30, \mathrm{P}=0.036)$ in the second ERCP compared with the first ERCP. The biochemistry indices of serum amylase and total bilirubin levels $24 \mathrm{~h}$ following the operation showed no obvious changes. A total of 6 of $94(6.25 \%)$ patients succumbed within 30 days of their latest ERCP. Table III shows that the 30-day mortality in the patients who did not undergo a second ERCP was significantly higher compared with that in the patients who underwent a second ERCP. The causes of mortality were not related to ERCP; 1 patient underwent a second ERCP and 2 patients underwent PTBD, all of them succumbed from underlying advanced malignancy. The other 3 patients underwent radical surgery and died from surgery-related complications.

Adverse events. Among the 94 patients in whom initial cannulation failed, 9 adverse events were recorded (9.6\%); 5 occurred in patients who underwent a second ERCP. In total, the adverse events were not severe. After the first ERCP, 5 patients experienced mild PEP, 1 patient suffered duodenal perforation, 2 patients experienced mild cholangitis and 1 patient suffered delayed bleeding. After the second ERCP, 3 patients suffered moderate PEP and 2 patients experienced mild cholangitis. The duodenal perforation was repaired through the endoscopic channel. All cases of PEP and cholangitis were 
Table II. Characteristics of patients underwent a successful second ERCP.

\begin{tabular}{lccr}
\hline Characteristics & First ERCP & Second ERCP & P-value \\
\hline Median operative time, minutes (range) & $65(31-120)$ & $47(26-127)$ & $<0.001^{\text {a }}$ \\
Adverse events, $\mathrm{n}$ & $4(8.5 \%)$ & $3(6.4 \%)$ & $>0.999$ \\
Serum amylase 24 h after operation, median (range) $(\mathrm{U} / \mathrm{l})$ & $65(30-1265)$ & $86(30-1135)$ & 0.482 \\
Total bilirubin 24 h after operation, median (range) $(\mu \mathrm{mol} / \mathrm{l})$ & $30.8(5.5-559.9)$ & $29.8(9-645.9)$ & 0.623 \\
Cannulation techniques, $\mathrm{n}$ & $30(63.8 \%)$ & $39(74.5 \%)$ & $0.036^{\mathrm{a}}$ \\
NKS & 16 & 21 & \\
DGT & 14 & 18 & \\
\hline
\end{tabular}

${ }^{\text {a}} \mathrm{P}<0.05$. ERCP, endoscopic retrograde cholangiopancreatography; DGT, double-guidewire technique; NKS, Needle-knife sphincterotomy.

Table III. Results of comparison between the two groups with or without second ERCP.

\begin{tabular}{lccr}
\hline Variables & No repeat ERCP group $(\mathrm{n}=38)$ & Second ERCP group (n=56) & P-value \\
\hline Median age, years (range) & $68.5(41-92)$ & $67(18-89)$ & 0.755 \\
Sex (female), $\mathrm{n}$ & $24(63.2 \%)$ & $33(58.9 \%)$ & 0.680 \\
Hospital stay, median days (range) & $13(1-41)$ & $15(5-38)$ & 0.227 \\
First operation time, minutes & $58.5(25-140)$ & $64.5(31-120)$ & 0.280 \\
Cannulation technique on the first ERCP & $20(52.6 \%)$ & $35(62.5 \%)$ & 0.341 \\
NKS & 12 & 19 & \\
DGT & 8 & $4(7.1 \%)$ & 0.538 \\
Adverse events after the first ERCP, $\mathrm{n}$ & $5(13.2 \%)$ & $1(1.8 \%)$ & $0.038^{\mathrm{a}}$ \\
30-day mortality, any causes, $\mathrm{n}$ & $5(13.2 \%)$ & 0 & - \\
30-day mortality related to the ERCP, $\mathrm{n}$ & 0 & & \\
\hline
\end{tabular}

${ }^{\text {a}} \mathrm{P}<0.05$. ERCP, endoscopic retrograde cholangiopancreatography; DGT, double-guidewire technique; NKS, Needle-knife sphincterotomy.

treated conservatively and the patients recovered within a few days. There was no significant difference in adverse events following two ERCPs (4 vs. 3, P=1.000). There were also no adverse events between the second ERCP group and the no repeat ERCP group (Table III).

Risk factors for cannulation in the second ERCP failure. Table IV shows the results of univariate analysis for factors predicting cannulation failure in the second ERCP. Accordingly, the days between the two ERCP procedures (Fig. 2) and normal serum bilirubin levels (Fig. 3) were identified as significant factors for predicting cannulation failure in a second ERCP ( 3 days vs. 2 days, $\mathrm{P}=0.019,16$ vs. $7, \mathrm{P}=0.038$, respectively). Table $\mathrm{V}$ outlines the multivariate analysis results of the potential factors predicting cannulation failure of a second ERCP. Preoperative normal serum bilirubin levels $(\mathrm{OR}=9.211, \mathrm{P}=0.019)$ and an interval between the two ERCP procedures of $<3$ days $(\mathrm{OR}=6.765, \mathrm{P}=0.041)$ were identified as significant predictive factors for cannulation failure of a second ERCP.

\section{Discussion}

ERCP is now the primary minimally invasive approach for the diagnosis and treatment of a number of pancreaticobiliary diseases. Although studies have reported that the cannulation success rate has increased to 85 to $99 \%$ in experienced endoscopists with needle-knife assistance (22-24), the topic of selecting an optimal alternative among the multiple techniques that can be used subsequently following initial ERCP failure remains attractive. Previous studies have shown that a second ERCP within a few days is an efficient and safe treatment for clinically stable patients, with a success rate of $68-79 \%$ $(9,10,25-30)$. In the present study, the results showed that the overall success rate was $82.1 \%$ (47/56), which supports the feasibility of a second ERCP.

Repeated attempts often result in papilla edema and hyperemia, which makes the biliary cannulation more difficult. However, papilla edema can pathologically be alleviated over time and performing a second ERCP a few days following the initial failure may be an appropriate strategy to increase the success rate. A consensus has not yet been reached regarding the optimal interval time. Several studies have suggested that the interval time from the initial failed ERCP to the second one should be within the first 24-72 h $(16,29-34)$, while other studies suggested a delayed time of $4-7$ days $(9,10,25,27)$. Only one study revealed that the 4-day interval time was the only significant factor associated with failure in a second ERCP (9). In the present study, the median interval time between the 
Table IV. Results of univariate analysis for factors predicting cannulation failure in the second ERCP.

\begin{tabular}{lcrr}
\hline Factors & Success $(\mathrm{n}=47)$ & Failure $(\mathrm{n}=9)$ & P-value \\
\hline Median age, years (range) & $68(18-89)$ & $66(23-80)$ & 0.746 \\
Gender (female), $\mathrm{n}$ & $28(59.6 \%)$ & $5(55.6 \%)$ & $>0.999$ \\
Normal serum bilirubin, $\mathrm{n}$ & $16(34 \%)$ & $7(77.8 \%)$ & $0.038^{\mathrm{a}}$ \\
Indications, malignant, $\mathrm{n}$ & $22(46.8 \%)$ & $3(33.3 \%)$ & 0.705 \\
Complications after second ERCP, $\mathrm{n}$ & $4(8.5 \%)$ & $1(11.1 \%)$ & $>0.999$ \\
NKS on the second ERCP, n & $15(31.9 \%)$ & $6(66.7 \%)$ & 0.143 \\
Days between ERCP, median (range) & $3(1-9)$ & $2(1-5)$ & $0.019^{\mathrm{a}}$
\end{tabular}

${ }^{a} \mathrm{P}<0.05$. ERCP, endoscopic retrograde cholangiopancreatography; NKS, Needle-knife sphincterotomy.

Table V. Results of multivariate analysis for factors predicting cannulation failure in the second ERCP (unconditional logistic regression).

\begin{tabular}{lccc}
\hline Factors & Odds ratio & 95\% CI & P-value \\
\hline Normal serum bilirubin & 9.211 & $1.446-58.658$ & $0.019^{\mathrm{a}}$ \\
Indications, malignant & 2.765 & $0.485-15.768$ & 0.225 \\
NKS on the second ERCP & 2.698 & $0.414-17.579$ & 0.299 \\
Interval between two ERCP $<3$ days & 6.765 & $1.086-42.151$ & $0.041^{\text {a }}$
\end{tabular}

${ }^{\mathrm{a}} \mathrm{P}<0.05$. ERCP, endoscopic retrograde cholangiopancreatography; NKS, Needle-knife sphincterotomy.



Figure 2. The interval time in the success and failure group. There was a significantly statistical difference in the interval time between the succussful and failed second ERCP group ( 3 days vs. 2 days, $\mathrm{P}=0.019$ ). $\mathrm{n}$ (succuss group) $=47, \mathrm{n}$ (failure group) $=9$. The result was present as median and analyzed by Mann-Whitney $\mathrm{U}$ test. ${ }^{*} \mathrm{P}<0.05$. ERCP, endoscopic retrograde cholangiopancreatography.

two ERCP procedure was 3 days and there was a statistically significant difference in the interval time between the

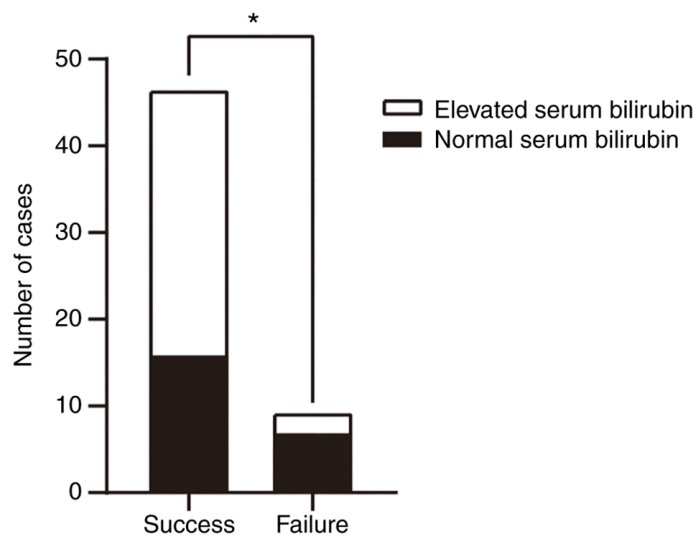

Figure 3. The number of cases with normal or elevated serum bilirubin in the success and failure group. There was a significantly statistical difference in normal serum bilirubin between the succussful and failed second ERCP group (16 vs. $7, \mathrm{P}=0.038$ ). The result was present as frequency and analyzed by the Pearson's corrected Chi-square test. ${ }^{*} \mathrm{P}<0.05$. ERCP endoscopic retrograde cholangiopancreatography.

successful and failed groups ( 3 days vs. 2 days, $\mathrm{P}=0.019$ ). It was found by multivariate analysis that an interval time less than 3 days was closely associated to the second ERCP failure. According to previous studies, the papilla edema caused by initial cannulation attempts and cautery always resolves in 3-5 days and the papilla can be detected with a clear appearance following this period $(10,26)$. However, in the practical work, it was observed that the mild edematous papilla at the first 1 2 days was clear enough for cannulation. Moreover, with 
the improvement of perioperative management, patients can recover quickly from the initial procedure. Thus, there is no need to spend more than 4 days waiting for the improvement of hyperemia and edema, because there is evidence showing that the incidence of adverse events might increase. Since an interval time $<1$ day is the highest risk factor reported by most previous studies $(10,26,32,33)$, the present study suggested that a 2-4 day interval time might be suitable for most patients with stable clinical conditions.

Currently, a number of advanced cannulation techniques have been applied that can help to significantly increase the cannulation success rate. Most previous studies reported the data of patients who underwent a second ERCP following the initial failure following precut sphincterotomy $(9,10,25-27,31,33,34)$. However, both patients with or without initial precut were included in the present study. One reason for this was that some studies have reported that in experienced hands, the early implementation of precut and persistent cannulation attempts have similar overall cannulation rates and the need for precut sphincterotomy decreased $(4,33,34)$. On the other hand, to preserve the function of the sphincter of Oddi and reduce the incidence of complications where possible, we did not routinely use the precut technique. The results in the present study also showed that the initial needle-knife sphincterotomy was not a risk factor for a second failure cannulation. It was observed that compared with the first ERCP, the frequencies of advanced cannulation techniques were increased (30 vs. 39 , $\mathrm{P}=0.036$ ) and the operative time was decreased (65 min vs. $47 \mathrm{~min}, \mathrm{P}<0.001)$ for the second ERCP. These results might indicate that it was more conducive to apply the advanced techniques which would make the procedure easier, than the initial ERCP.

It is known that difficult biliary cannulation can increase the risk of post-ERCP adverse events, such as PEP, cholangitis, bleeding and perforation and contribute to a negative impact on a variety of clinical outcomes $(35,36)$. In the present study, severe ERCP-related complications or other adverse events in relation to the operation delay were not observed. In addition, following the second ERCP, there was no significant difference in the incidence of adverse events compared to the initial procedure. The second ERCP did not increase the additional risk of adverse events, which was consistent with previous studies (10,25-29). Therefore, it is a safe option of performing a second ERCP following the initial ERCP failed.

When the 30-day mortality of the included patients was followed up, it was observed that the mortality within 30 days was higher in the group without a second ERCP than in the group with a second ERCP. Meanwhile, for all the 6 patients who succumbed, their indication for ERCP was malignant stricture. The causes of death were not associated with ERCP. To the authors' knowledge, most patients with malignant stricture had to receive palliative biliary drainage when they missed the opportunity for radical surgery. These patients often died from diseases progression. In addition, the possible complications associated with radical surgery could also increase mortality. These results were similar to some other studies $(10,28,37)$. The results of the present study meant that successful biliary access might be a good prognostic factor for malignant patients within a certain period of time.
At present, our knowledge about failure in a second ERCP is limited. The likelihood of successful cannulation is influenced by operator factors (experience) and patient factors (anatomy), which is stated in the ESGE guidelines for papillary cannulation (15). In the present retrospective study, all of the ERCP procedures were performed by one experienced endoscopist, which may limit possible confounding factors resulting from the varying skill of the operators. However, patient factors, including abnormal duodenal papilla, twisting or stenosis of the distal bile duct, fast bowel motility, intradivertiucular or peridiverticular papilla and surgically altered anatomy, usually directly increase the operating difficulty, which may result in a decreased success rate $(5-7,18,38)$. The present study found that preoperative normal serum bilirubin level was a risk factor that correlated with failure in a second ERCP $(\mathrm{OR}=6.702, \mathrm{P}=0.034)$ by multivariate analysis. Normal preoperative serum bilirubin levels always indicate the presence of a small common bile duct diameter or sphincter of Oddi dysfunction, which could contribute to difficult cannulation (15,21,39-42). Meanwhile, for the patients with asymptomatic common bile duct stones, their bilirubin levels are always normal $(43,44)$. Generally, a smaller papillary orifice is associated with difficult cannulation (45). Compared to symptomatic common bile duct stones, the papillary orifice might be smaller in asymptomatic common bile duct stones because of low bile duct pressure secondary to the absence of cholestasis (44). Although previous studies and the ESGE guidelines for ERCP-related adverse events have stated that normal serum bilirubin is an independent risk factor for PEP $(35,39,46)$, to the best of the authors' knowledge, the relationship between normal serum bilirubin and unsuccessful outcomes in second ERCP has not been well reported. Based on the results of the present study, it is suggested that endoscopists should give careful consideration to select patients with normal serum bilirubin levels when performing a second ERCP.

As this was a retrospective nonrandomized study, it has limitations such as selection bias, a single center, incomplete data and an insufficient number of patients. Perhaps the one endoscopist in our center was highly experienced, so the overall number of initial failure patients was not large enough and it was also difficult to conduct a prospective randomized study. Other confounding factors, such as the sizes and morphologies of the papilla and the duodenum diverticulum, were not included due to incomplete data. In spite of these limitations the present study summarized the available data from our database and these results are meaningful for clinical practice to some extent.

In conclusion, a second ERCP following failure of an initial biliary cannulation appeared to be safe and effective. For most clinically stable patients with an unsuccessful initial ERCP, a second ERCP after 2-4 days may be an optimal strategy. Preoperative normal serum bilirubin levels may be a risk factor that can be used for predicting cannulation failure of a second ERCP procedure.

\section{Acknowledgements}

Not applicable. 


\section{Funding}

This study was funded by the Basic and Advanced Research Project of Science and Technology Commission of Chongqing Municipality (grant no. cstc2018jcyjAX0162).

\section{Availability of data and materials}

The datasets used and/or analyzed during the current study are available from the corresponding author on reasonable request.

\section{Authors' contributions}

XD and QW confirm the authenticity of all the raw data. XD and QW designed the study. CD reviewed the study proposal. XD, RL and LP collected and analyzed the data. XD, QW and $\mathrm{CD}$ interpreted the results. XD and RL prepared the figures and drafted the manuscript. QW, LP and CD edited and revised the manuscript. All authors have read and approved the final manuscript.

\section{Ethics approval and consent to participate}

The study was conducted according to the guidelines of the Declaration of Helsinki and approved by the ethics committee of the First Affiliated Hospital of Chongqing Medical University (approval no. 2020-668). Informed consent was obtained from all subjects involved in the study.

\section{Patient consent for publication}

Not applicable.

\section{Competing interests}

The authors declare that they have no competing interests.

\section{References}

1. Lee YS, Cho CM, Cho KB, Heo J, Jung MK, Kim SB, Kim KH, Kim TN, Lee DW, Han J, et al: Difficult biliary cannulation from the perspective of post-endoscopic retrograde cholangiopancreatography pancreatitis: Identifying the optimal timing for the rescue cannulation technique. Gut Liver 15: 459-465, 2021.

2. Nakai Y,IsayamaH,Sasahira N,Kogure H,Sasaki T, Yamamoto N, Saito K, Umefune G, Akiyama D, Kawahata S, et al: Risk factors for post-ERCP pancreatitis in wire-guided cannulation for therapeutic biliary ERCP. Gastrointest Endosc 81: 119-126, 2015.

3. Chen Q, Jin P, Ji X, Du H and Lu J: Management of difficult or failed biliary access in initial ERCP: A review of current literature. Clin Res Hepatol Gastroenterol 43: 365-372, 2019.

4. Cennamo V,FuccioL,ZagariRM,Eusebi LH,Ceroni L,LaterzaL, Fabbri C and Bazzoli F: Can early precut implementation reduce endoscopic retrograde cholangiopancreatography-related complication risk? Meta-analysis of randomized controlled trials. Endoscopy 42: 381-388, 2010.

5. Williams EJ, Ogollah R, Thomas P, Logan RF, Martin D, Wilkinson ML and Lombard M: What predicts failed cannulation and therapy at ERCP? Results of a large-scale multicenter analysis. Endoscopy 44: 674-683, 2012.

6. Altonbary AY and Bahgat MH: Endoscopic retrograde cholangiopancreatography in periampullary diverticulum: The challenge of cannulation. World J Gastrointest Endosc 8: 282-287, 2016.

7. Krutsri C, Kida M, Yamauchi $\mathrm{H}$, Iwai $\mathrm{T}$, Imaizumi $\mathrm{H}$ and Koizumi W: Current status of endoscopic retrograde cholangiopancreatography in patients with surgically altered anatomy. World J Gastroenterol 25: 3313-3333, 2019.
8. ASGE Technology Committee, Enestvedt BK, Kothari S, Pannala R, Yang J, Fujii-Lau LL, Hwang JH, Konda V, Manfredi M, Maple JT, et al: Devices and techniques for ERCP in the surgically altered GI tract. Gastrointest Endosc 83: 1061-1075, 2016.

9. Colan-Hernandez J, Aldana A, Concepción M, Chavez K, Gómez C, Mendez-Bocanegra A, Martínez-Guillen M, Sendino O, Villanueva C, Llach J, et al: Optimal timing for a second ERCP after failure of initial biliary cannulation following precut sphincterotomy: An analysis of experience at two tertiary centers. Surg Endosc 31: 3711-3717, 2017.

10. Pavlides M, Barnabas A, Fernandopulle N, Bailey AA, Collier J, Phillips-Hughes J, Ellis A, Chapman R and Braden B: Repeat endoscopic retrograde cholangiopancreaticography after failed initial precut sphincterotomy for biliary cannulation. World $\mathrm{J}$ Gastroenterol 20: 13153-13158, 2014.

11. Bokemeyer A, Muller F, Niesert H, Brückner M, Bettenworth D, Nowacki T, Beyna T, Ullerich H and Lenze F: Percutaneous-transhepatic-endoscopic rendezvous procedures are effective and safe in patients with refractory bile duct obstruction. United European Gastroenterol J 7: 397-404, 2019.

12. Lorenz JM: Management of malignant biliary obstruction. Semin Intervent Radiol 33: 259-267, 2016.

13. Abbas AM, Strong AT, DiehlDL, Brauer BC, Lee IH, Burbridge R, Zivny J, Higa JT, Falcão M, El Hajj II, et al: Multicenter evaluation of the clinical utility of laparoscopy-assisted ERCP in patients with Roux-en-Y gastric bypass. Gastrointest Endosc 87: 1031-1039, 2018

14. Huang RJ, Thosani NC, Barakat MT, Choudhary A, Mithal A, Singh G, Sethi S and Banerjee S: Evolution in the utilization of biliary interventions in the United States: Results of a nationwide longitudinal study from 1998 to 2013. Gastrointest Endosc 86: 319-326.e5, 2017

15. Testoni PA, Mariani A, Aabakken L, Arvanitakis M, Bories E, Costamagna G, Devière J, Dinis-Ribeiro M, Dumonceau JM, Giovannini M, et al: Papillary cannulation and sphincterotomy techniques at ERCP: European society of gastrointestinal endoscopy (ESGE) clinical guideline. Endoscopy 48: 657-683, 2016.

16. Liao WC, Angsuwatcharakon P, Isayama H, Dhir V, Devereaux B, Khor CJ, Ponnudurai R, Lakhtakia S, Lee DK, Ratanachu-Ek T, et al: International consensus recommendations for difficult biliary access. Gastrointest Endosc 85: 295-304, 2017.

17. Haraldsson E, Kylänpää L, Grönroos J, Saarela A, Toth E, Qvigstad G, Hult M, Lindström O, Laine S, Karjula H, et al: Macroscopic appearance of the major duodenal papilla influences bile duct cannulation: A prospective multicenter study by the scandinavian association for digestive endoscopy study group for ERCP. Gastrointest Endosc 90: 957-963, 2019.

18. Chen PH, Tung CF, Peng YC, Yeh HZ, Chang CS and Chen CC: Duodenal major papilla morphology can affect biliary cannulation and complications during ERCP, an observational study. BMC Gastroenterol 20: 310, 2020.

19. ASGE Training Committee, Jorgensen J, Kubiliun N, Law JK, Al-Haddad MA, Bingener-Casey J, Christie JA, Davila RE, Kwon RS, Obstein KL, et al: Endoscopic retrograde cholangiopancreatography (ERCP): Core curriculum. Gastrointest Endosc 83: 279-289, 2016

20. Wani S, Han S, Simon V, Hall M, Early D, Aagaard E, Abidi WM, Banerjee S, Baron TH, Bartel M, et al: Setting minimum standards for training in EUS and ERCP: Results from a prospective multicenter study evaluating learning curves and competence among advanced endoscopy trainees. Gastrointest Endosc 89: 1160-1168.e9, 2019.

21. ASGE Standards of Practice Committee, Chandrasekhara V, Khashab MA, Muthusamy VR, Acosta RD, Agrawal D, Bruining DH, Eloubeidi MA, Fanelli RD, Faulx AL, et al: Adverse events associated with ERCP. Gastrointest Endosc 85: 32-47, 2017.

22. Williams EJ, Taylor S, Fairclough P, Hamlyn A, Logan RF, Martin D, Riley SA, Veitch P, Wilkinson M, Williamson PR, et al: Are we meeting the standards set for endoscopy? Results of a large-scale prospective survey of endoscopic retrograde cholangio-pancreatograph practice. Gut 56: 821-829, 2007.

23. Jin YJ, Jeong S and Lee DH: Utility of needle-knife fistulotomy as an initial method of biliary cannulation to prevent post-ERCP pancreatitis in a highly selected at-risk group: A single-arm prospective feasibility study. Gastrointest Endosc 84: 808-813, 2016. 
24. Fiocca F, Fanello G, Cereatti F, Maselli R, Ceci V and Donatelli G: Early 'shallow' needle-knife papillotomy and guidewire cannulation: An effective and safe approach to difficult papilla. Therap Adv Gastroenterol 8: 114-120, 2015.

25. Kevans D, Zeb F, Donnellan F, Courtney G and Aftab AR: Failed biliary access following needle knife fistulotomy: Is repeat interval ERCP worthwhile? Scand J Gastroenterol 45: 1238-1241, 2010.

26. Kim J, Ryu JK, Ahn DW, Park JK, Yoon WJ, Kim YT and Yoon YB: Results of repeat endoscopic retrograde cholangiopancreatography after initial biliary cannulation failure following needle-knife sphincterotomy. J Gastroenterol Hepatol 27: 516-520, 2012.

27. Donnellan F, Enns R, Kim E, Amar J, Telford J and Byrne MF: Outcome of repeat ERCP after initial failed use of a needle knife for biliary access. Dig Dis Sci 57: 1069-1071, 2012.

28. Lo MH, Lin CH, Wu CH, Tsou YK, Lee MH, Sung KF and Liu NJ: Management of biliary diseases after the failure of initial needle knife precut sphincterotomy for biliary cannulation. Sci Rep 11: 14968, 2021.

29. Peñaloza Ramírez A, Rodríguez Tello D, Murillo Arias A, Barreto Pérez J and Aponte Ordóñez P: Endoscopic retrograde cholangiopancreatography results three days after a failed pre-cut. Rev Esp Enferm Dig 113: 486-489, 2021.

30. Flumignan VK, Seike MG, Souza VS, Cirqueira MI, Silva AB and Artifon ELA: Difficult biliary cannulation: Should we always try a second ercp after a failed needle-knife fistulotomy? Arq Gastroenterol 58: 509-513, 2021.

31. Kaffes AJ, Sriram PV, Rao GV, Santosh D and Reddy DN: Early institution of pre-cutting for difficult biliary cannulation: A prospective study comparing conventional vs. a modified technique. Gastrointest Endosc 62: 669-674, 2005.

32. Ang TL, Kwek AB, Lim KB, Teo EK and Fock KM: An analysis of the efficacy and safety of a strategy of early precut for biliary access during difficult endoscopic retrograde cholangiopancreatography in a general hospital. J Dig Dis 11: 306-312, 2010.

33. Harewood GC and Baron TH: An assessment of the learning curve for precut biliary sphincterotomy. Am J Gastroenterol 97: $1708-1712,2002$

34. Akaraviputh T, Lohsiriwat V, Swangsri J, Methasate A, Leelakusolvong S and Lertakayamanee $\mathrm{N}$ : The learning curve for safety and success of precut sphincterotomy for therapeutic ERCP: A single endoscopist's experience. Endoscopy 40: 513-516, 2008

35. Dumonceau JM, Kapral C, Aabakken L, Papanikolaou IS, Tringali A, Vanbiervliet G, Beyna T, Dinis-Ribeiro M, Hritz I, Mariani A, et al: ERCP-related adverse events: European society of gastrointestinal endoscopy (ESGE) guideline. Endoscopy 52: $127-149,2020$

36. Fung BM,Pitea TC and Tabibian JH: Difficult biliary cannulation in endoscopic retrograde cholangiopancreatography: Definitions, risk factors, and implications. Eur Med J Hepatol 9: 64-72, 2021.
37. Halttunen J, Meisner S, Aabakken L, Arnelo U, Grönroos J, Hauge T, Kleveland PM, Nordblad Schmidt P, Saarela A, Swahn F, et al: Difficult cannulation as defined by a prospective study of the scandinavian association for digestive endoscopy (SADE) in 907 ERCPs. Scand J Gastroenterol 49: 752-758, 2014.

38. Watanabe M, Okuwaki K, Kida M, Imaizumi H, Yamauchi H, Kaneko T, Iwai T, Hasegawa R, Miyata E, Masutani H, et al: Transpapillary biliary cannulation is difficult in cases with large oral protrusion of the duodenal papilla. Dig Dis Sci 64: 2291-2299, 2019.

39. Freeman ML, DiSario JA, Nelson DB, Fennerty MB, Lee JG Bjorkman DJ, Overby CS, Aas J, Ryan ME, Bochna GS, et al: Risk factors for post-ERCP pancreatitis: A prospective, multicenter study. Gastrointest Endosc 54: 425-434, 2001.

40. Saito H, Kadono Y, Shono T, Kamikawa K, Urata A, Nasu J, Imamura H, Matsushita I, Kakuma T and Tada S: Factors predicting difficult biliary cannulation during endoscopic retrograde cholangiopancreatography for common bile duct stones. Clin Endosc: Nov 12, 2021 (Epub ahead of print).

41. Zhou PH, Yao LQ, Xu MD, Zhong YS, Gao WD, He GJ, Zhang YQ, Chen WF and Qin XY: Application of needle-knife in difficult biliary cannulation for endoscopic retrograde cholangiopancreatography. Hepatobiliary Pancreat Dis Int 5: 590-594, 2006.

42. Lopes L, Canena J, Fernandes J, Moreira M, Costa I, Gomes-Fonseca J, Araújo T, Alexandrino G, Lourenço L, Horta D, et al: Should we use papilla morphology to estimate the size of the terminal common bile duct during endoscopic retrograde cholangiopancreatography? Eur J Gastroenterol Hepatol 32: 181-186, 2020.

43. Xiao L, Geng C, Li X, Li Y and Wang C: Comparable safety of ERCP in symptomatic and asymptomatic patients with common bile duct stones: A propensity-matched analysis. Scand J Gastroenterol 56: 111-117, 2021.

44. Kadokura M, Takenaka Y, Yoda H, Yasumura T, Okuwaki T, Tanaka K and Amemiya F: Asymptomatic common bile duct stones are associated with increased risk of post-endoscopic retrograde cholangiopancreatography pancreatitis. JMA J 4: 141-147, 2021.

45. Kuo CM, Chiu YC, Changchien CS, Tai WC, Chuah SK, Hu TH, Kuo YH and Kuo CH: Endoscopic papillary balloon dilation for removal of bile duct stones: Evaluation of outcomes and complications in 298 patients. J Clin Gastroenterol 46: 860-864, 2012.

46. Testoni PA, Mariani A, Giussani A, Vailati C, Masci E, Macarri G, Ghezzo L, Familiari L, Giardullo $\mathrm{N}$ and Mutignani M, et al: Risk factors for post-ERCP pancreatitis in high- and low-volume centers and among expert and non-expert operators: A prospective multicenter study. Am J Gastroenterol 105: 1753-1761, 2010.

This work is licensed under a Creative Commons Attribution-NonCommercial-NoDerivatives 4.0 International (CC BY-NC-ND 4.0) License. 